\title{
Lignitic Humic Acids as Environmentally-Friendly Adsorbent for Heavy Metals
}

\author{
Martina Klučáková ${ }^{1}$ and Marcela Pavlíková ${ }^{2}$ \\ ${ }^{1}$ Materials Research Centre, Faculty of Chemistry, Brno University of Technology, Purkyňova 118, 61200 Brno, Czech Republic \\ ${ }^{2}$ Institute of Chemistry, Faculty of Civil Engineering, Brno University of Technology, Žižkova 17, 60200 Brno, Czech Republic
}

Correspondence should be addressed to Martina Klučáková; klucakova@fch.vutbr.cz

Received 15 December 2016; Accepted 22 January 2017; Published 5 March 2017

Academic Editor: Ziya A. Khan

Copyright (C) 2017 Martina Klučáková and Marcela Pavlíková. This is an open access article distributed under the Creative Commons Attribution License, which permits unrestricted use, distribution, and reproduction in any medium, provided the original work is properly cited.

Humic acids are a part of humus material, are abundant in nature, and form a substantial pool of natural organic matter. They participate in the transport of both beneficial and harmful species. Due to their structure and properties, they can interact with metal ions and, with them, form relatively stable complexes. These substances are thus responsible for the so-called self-cleaning ability of soils. Lignite as a young coal type contains a relatively high amount of humic acids which can be used as an environmentallyfriendly adsorbent for heavy metals. In this work, we compared the adsorption of single $\mathrm{Cu}^{2+}$ ions with the simultaneous adsorption of several different metal ions $\left(\mathrm{Cd}^{2+}, \mathrm{Cu}^{2+}, \mathrm{Pb}^{2+}\right.$, and $\left.\mathrm{Zn}^{2+}\right)$. The adsorption efficiency of humic acids was very high, almost $100 \%$ in the case of the single adsorption of $\mathrm{Cu}^{2+}$ ions and more than $90 \%$ for the adsorption from the mixture of metal ions. The stability of formed complexes, considered on the basis of the leaching in different extraction agents, was higher than $80 \%$; only 9-18\% was in the mobile phase. After adsorption, metal ions are contained in humic acids after adsorption in mainly strongly bonded form $(60-73 \%)$ and can be liberated from their structure only in low amounts.

\section{Introduction}

One of the most characteristic properties of humic substances is their adsorption ability [1-4]. They can bind to heavy metal ions, which are characterized by high toxicity and the ability to accumulate in the environment, and in this way, they can influence the effectiveness of regeneration and purification processes in soil and aqueous systems. Hence, the immobilization or removal of toxic metals is a research goal as well as an industrial task [5-7]. A cost-effective and environmentally-friendly approach is the use of sorption technology based on the use of sorbents prepared from some biomaterial $[8,9]$. A potential low-cost sorbent of toxic metals and radionuclides for use in water treatment and groundwater remediation is lignite [2, 9-11]. When humic acids, as the most active constituents, were isolated from lignite and used as an adsorbent for metal ions, their effectivity and sorption capacity substantially increased [2]. In comparison with humic acids isolated from various soil types, lignitic humic acids exhibit a very high sorption capacity and a low degree of desorption $[6,12]$. On the other hand, humic acids isolated from oxyhumolite exhibited a lower sorption capacity in comparison with humic soil-derived humic acids [13]. The removal of heavy metals from aqueous systems such as waste streams employs various technologies which are often either expensive or inefficient, especially when very low residual concentrations compliant with health-based limits are required $[7,8]$. On the basis of previous results, lignitic humic acids were used in this work for the environmentallyfriendly adsorption of metal ions.

Interactions between humic acids and metal ions have a complex nature given by their heterogeneous, polyelectrolyte, and polydispersive character. Metal ions can bond with humic acids in several different ways from the purely electrostatic, nonspecific interaction of metal cation with the net negative charge on the surface of a humic particle to specific interactions in the formation of complexes and chelates with functional groups $[1,2,4,7,14-16]$. Due to the heterogeneous character of humic acids and their partial solubility in water, they can form water-soluble and water 
TABLE 1: Elemental analysis of lignitic humic acids (normalized on dry ash-free sample).

\begin{tabular}{lcccc}
\hline $\mathrm{C}$ & $\mathrm{H}$ & $\mathrm{N}$ & $\mathrm{S}$ & $\mathrm{O}$ \\
\hline $42.7 \%$ at. & $41.8 \%$ at. & $0.9 \%$ at. & $0.3 \%$ at. & $14.3 \%$ at. \\
\hline
\end{tabular}

insoluble complexes with metal ions and other pollutants [4, 17-21]. Humic acids of low molecular weight had a much higher sorption capacity than those of high molecular weight or unfractionated humic material [13]. It was found that the binding of metals to humic acids depends on their type. The sorption capacity of humic acids for some metals is much higher than their possibilities given by the content of functional groups $[4,16]$. Metal ions are bound to humic acids by different strengths and particular metals can exist in humic material in several different fractions [4, 22-26].

This work follows our previous adsorption studies $[2,4,6]$ and is focused mainly on potential industrial applications such as the removal of heavy metals from waters, with an emphasis on the (often problematic) issue of low concentrations and the stability of the formed complexes.

\section{Materials and Methods}

Humic acids (HA) were extracted from South-Moravia lignite using a mixture of $\mathrm{NaOH}$ and $\mathrm{Na}_{4} \mathrm{P}_{2} \mathrm{O}_{7}$ by means of a procedure described in our previous studies $[4,6]$ and characterized previously $[4,6,27,28]$. Elemental analysis was carried out using a CHNSO Microanalyser Flash 1112 (Carlo Erba). The obtained values are listed in Table 1.

Humic acids and metal ion solutions $\left(\mathrm{CdCl}_{2}, \mathrm{CuCl}_{2}\right.$, $\mathrm{PbCl}_{2}$, and $\mathrm{ZnCl}_{2}$, Sigma-Aldrich) were mixed in the ratio $1 \mathrm{~g} / 50 \mathrm{~mL}$ and stirred to equilibrium $(24 \mathrm{~h})$. Then, solid humic particles were sequestered by centrifugation and the supernatant was analyzed. The quantity of the adsorbed amount was determined on the basis of the decrease in the metal ion concentration in the solution during sorption.

The stability of the formed complexes was studied using the extraction of metal ions by different agents. Water was used for the extraction of the mobile fraction (free unbound metal ions). A $1 \mathrm{M} \mathrm{MgCl}_{2}$ solution was used as the extraction agent for the ion-exchangeable fraction (weakly bound metal ions). The strongly bound fraction of metal ions was extracted by a $1 \mathrm{M} \mathrm{HCl}$ solution. The extraction agents were chosen on the basis of results published in previous works $[12,29,30]$.

The concentrations of metal ions in different solutions were measured by electrode coulometric titration (EcaFlow 150 GLP), based on the direct electrochemical conversion of the analyte species in the pores of the electrode or in a thin layer [17]. Metal ions were electrochemically deposited from the flowing sample solution onto the porous working electrode. The deposition was performed by applying a suitable potential. In the next step, the deposit was stripped galvanostatically and the stripping chronopotentiogram was recorded and evaluated.

All experiments were made in triplicate at $25^{\circ} \mathrm{C}$ (in an airconditioned laboratory). The data are presented as average values with standard deviation.
TABLE 2: Average adsorption efficiencies for single $\mathrm{Cu}^{2+}$ ions and $\mathrm{Cd}^{2+}, \mathrm{Cu}^{2+}, \mathrm{Pb}^{2+}$, and $\mathrm{Zn}^{2+}$ ions adsorbed from their mixture.

\begin{tabular}{lcccc}
\hline $\mathrm{Cu}^{2+}$ (single) & $\mathrm{Cd}^{2+}$ & $\mathrm{Cu}^{2+}$ & $\mathrm{Pb}^{2+}$ & $\mathrm{Zn}^{2+}$ \\
\hline $99.9 \%$ & $90.3 \%$ & $94.4 \%$ & $92.8 \%$ & $92.0 \%$ \\
\hline
\end{tabular}

TABLE 3: Average participation in total adsorption amount for $\mathrm{Cd}^{2+}$, $\mathrm{Cu}^{2+}, \mathrm{Pb}^{2+}$, and $\mathrm{Zn}^{2+}$ ions adsorbed from their mixture.

\begin{tabular}{lccc}
\hline $\mathrm{Cd}^{2+}$ & $\mathrm{Cu}^{2+}$ & $\mathrm{Pb}^{2+}$ & $\mathrm{Zn}^{2+}$ \\
\hline $21.0 \%$ & $23.7 \%$ & $31.7 \%$ & $23.6 \%$ \\
\hline
\end{tabular}

\section{Results and Discussion}

In this work, the adsorption from low concentration metal ion solutions by solid humic acids was studied. We compared the adsorption of single $\mathrm{Cu}^{2+}$ ions with simultaneous adsorption of several different metal ions $\left(\mathrm{Cd}^{2+}, \mathrm{Cu}^{2+}, \mathrm{Pb}^{2+}\right.$, and $\left.\mathrm{Zn}^{2+}\right)$. This concentration region was chosen on the basis of the potential utilization of humic substances as a low-cost sorbent for environmentally-friendly adsorption of toxic metal ions often occurring in low but still problematic and harmful concentrations. As we can see, the efficiency of adsorption in the case of single $\mathrm{Cu}^{2+}$ ions was almost $100 \%$ in the used concentration range. Its value slightly decreased with respect to adsorption from the mixture of metal ions, but the average efficiency was higher than $90 \%$ for all metal ions used (see Table 2).

The real efficiency fluctuated by 80 and $100 \%$ with the initial concentrations of metal ions (see Figure 1). Their values were thus very high over the whole concentration range and no specific trend was observed.

Comparing the percentages of metal ions that were adsorbed we can see that the most readily adsorbed metal was lead. Copper and zinc were adsorbed to a similar extent. Cadmium exhibited the lowest percentage, but its adsorption was only little worse than in the case of copper and zinc (see Table 3).

Since, the efficiency of adsorption was in many cases 100\% and the used concentrations were low, it was not possible to fit experimental data by any of the usually used adsorption isotherms. We determined the "distribution coefficient" as the slope obtained from the dependence of adsorbed amount on equilibrium concentration, where data with efficiency lower than $100 \%$ were used (zero equilibrium concentrations for $100 \%$ adsorption efficiency were not included in the calculation). The highest values were obtained for the single adsorption of $\mathrm{Cu}^{2+}$ ions; in the case of adsorption from the mixture, this metal also had the highest distribution coefficient. Strong adsorption was also found for $\mathrm{Pb}^{2+}$. On the other hand, the adsorption of $\mathrm{Zn}^{2+}$ was, according to the "distribution coefficient," relatively weak. The obtained values of the "distribution coefficient" are not fully in agreement with the results listed in Tables 2 and 3. The reason is the above-mentioned partial elimination of some adsorption data because of the zero equilibrium concentration. Therefore, these values can be considered only as complementary 

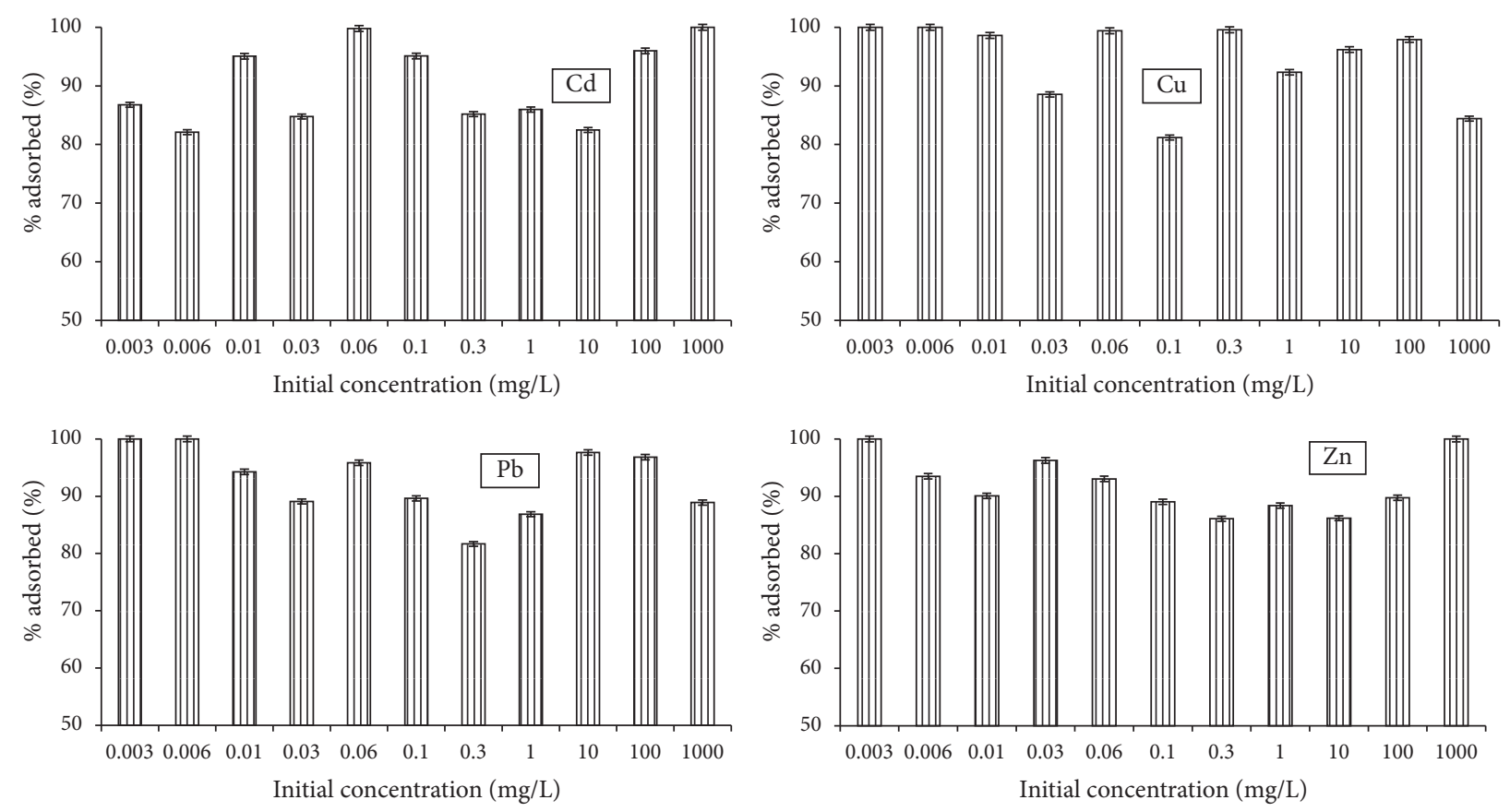

FIgURE 1: Amounts of metal ions adsorbed in dependence on their initial concentration in the mixture.

TABLE 4: Distribution coefficient for single $\mathrm{Cu}^{2+}$ ions and $\mathrm{Cd}^{2+}$, $\mathrm{Cu}^{2+}, \mathrm{Pb}^{2+}$, and $\mathrm{Zn}^{2+}$ ions adsorbed from their mixture.

\begin{tabular}{lcccc}
\hline $\mathrm{Cu}^{2+}$ (single) & $\mathrm{Cd}^{2+}$ & $\mathrm{Cu}^{2+}$ & $\mathrm{Pb}^{2+}$ & $\mathrm{Zn}^{2+}$ \\
\hline $0.902 \mathrm{~L} / \mathrm{g}$ & $0.236 \mathrm{~L} / \mathrm{g}$ & $0.627 \mathrm{~L} / \mathrm{g}$ & $0.423 \mathrm{~L} / \mathrm{g}$ & $0.135 \mathrm{~L} / \mathrm{g}$ \\
\hline
\end{tabular}

TABLE 5: Average contents of mobile phase, ion-exchangeable phase, strongly bound phase, and residual phase of single $\mathrm{Cu}^{2+}$ ions and $\mathrm{Cd}^{2+}, \mathrm{Cu}^{2+}, \mathrm{Pb}^{2+}$, and $\mathrm{Zn}^{2+}$ ions adsorbed from their mixture.

\begin{tabular}{lccccc}
\hline & $\begin{array}{c}\mathrm{Cu}^{2+} \\
(\text { single })\end{array}$ & $\mathrm{Cd}^{2+}$ & $\mathrm{Cu}^{2+}$ & $\mathrm{Pb}^{2+}$ & $\mathrm{Zn}^{2+}$ \\
\hline $\begin{array}{l}\text { Mobile phase } \\
\begin{array}{l}\text { Ion-exchangeable } \\
\text { phase }\end{array}\end{array}$ & $9.8 \%$ & $14.4 \%$ & $11.2 \%$ & $12.4 \%$ & $17.8 \%$ \\
$\begin{array}{l}\text { Strongly bound } \\
\text { phase }\end{array}$ & $22.2 \%$ & $29.2 \%$ & $23.6 \%$ & $23.1 \%$ & $26.7 \%$ \\
\begin{tabular}{l} 
Residual phase \\
\hline
\end{tabular} & $51.0 \%$ & $30.7 \%$ & $47.2 \%$ & $45.2 \%$ & $33.7 \%$ \\
\hline
\end{tabular}

ones for the complex illustration of the studied adsorption (see Table 4).

Although the average proportions of copper and zinc in the total adsorption amount were practically the same, their distributions according to bond strength were different. As we can see in Table 5, zinc was bound less strongly and larger part was present in mobile or ion-exchangeable form. Cadmium exhibited a similar content in the weakly bound mobile or ion-exchangeable form. On the other hand, copper and lead were bound strongly and only a small amount of these metals could be leached, for example, to water in nature. As can be seen, the individual extraction agents were able to leach different amounts of metal ions, which correspond with different affinities of humic acids to the metal. Water is a weak leaching agent, which can extract only mobile fractions of metal ions. In order to obtain the ion-exchangeable fraction of metal ions a $1 \mathrm{M} \mathrm{MgCl}$ solution was used. Metal ions extractable by a $1 \mathrm{M} \mathrm{HCl}$ solution constitute the fraction of strongly bound metal ions [12, 22, 29, 30]. Garcia-Mina [31] showed that the solubility of metal-humic complexes decreased with an increase in the metal: humic ratio, which could be related to the gradual reduction of the free ionized functional group in line with this increase. Our results confirmed this trend only partially, probably because of the use of low concentrations of metal ions. The strongly bound and residual phases were highest for copper and lead. These two metals were in large part strongly complexed in the humic structure and only a very small amount could be washed under normal conditions, as also confirmed by Dević [32]. Dudare and Klavins [33] showed that the complex stability constants significantly changed and were well correlated with the age and humification degree of humic acids. The lignitic humic acids used in our work belonged to the group of well-humified, more aromatic ones with a relatively high content of acidic functional groups, which predestines them for having a high complexation capacity for forming stable metal-humic complexes [7, 12, 34].

Our results correspond with some other works. Janoš et al. $[23,24]$ stated that $\mathrm{Cu}^{2+}$ and $\mathrm{Pb}^{2+}$ ions were bound very strongly to the sorbent and that only small portions of these metals could be extracted by weak agents. Substantial proportions of $\mathrm{Cu}^{2+}$ and $\mathrm{Pb}^{2+}$ ions remained in the residual fraction or were liberated only after the destruction of the organic matrix. On the other hand, $\mathrm{Cd}^{2+}$ and $\mathrm{Zn}^{2+}$ ions were retained less strongly in the sorbent, probably by an ion-exchange mechanism, and could be leached from the 
sorbent in acid media. Town and Van Leeuwen [26] obtained similar results for the adsorption of $\mathrm{Cd}^{2+}, \mathrm{Cu}^{2+}$, and $\mathrm{Pb}^{2+}$ ions. Bosire et al. [35] showed that $\mathrm{Zn}^{2+}$ and $\mathrm{Cu}^{2+}$ ions were statistically different in their adsorption capacities. Their surface complexation models showed stronger lead and copper interactions with monodentate sites compared to bidentate sites. According to their results, the ratio of $\mathrm{Pb}^{2+}$ ions adsorbed on monodentate carboxylic acid sites to $\mathrm{Pb}^{2+}$ ions adsorbed on bidentate sites was approximately $1: 1$. A similar trend was observed for $\mathrm{Cu}^{2+}$ ions. The participation of monodentate sites increased with temperature and phenolic sites were involved in bonding only weakly. Yang and Van Den Berg [36] and Kostić et al. [37] confirmed that humic complexes formed with copper exhibited greater stability than those formed with zinc. The stability constant for the complex between lead and humic acids was greater than those for other metal-humic complexes. Terbouche et al. [38] showed that the degree of association between metal ions and humic acids was greater for zinc than for cadmium, which corresponds with our results. Ren et al. [39] divided $\mathrm{Cd}^{2+}$, $\mathrm{Cu}^{2+}, \mathrm{Pb}^{2+}$, and $\mathrm{Zn}^{2+}$ ions occurring in contaminated soils into two groups: a fast exchangeable pool and a much slower exchangeable one. The distribution of the two exchangeable pools varied significantly among metals. The amount of cadmium related to the fast pool was dominant which could correspond with the highest amount of weakly bound $\mathrm{Cd}^{2+}$ ions found in this work. The authors stated that the exchange of cadmium was a relatively fast process, whereas the exchange of copper, lead, and zinc was more sluggish, which is of significant importance for the metal mobility, risk assessment, and management of contaminated soils.

Our results showed that the partitioning of metal ions according to bond strength depends on the presence of other metal ions. The strongly bound and residual fractions decreased in the case of adsorption from the mixture of metal ions, probably due to occupation of strong biding sites by other ions. This was connected with the decrease in adsorption efficiency when compared with the single adsorption of $\mathrm{Cu}^{2+}$ ions. On the other hand, the efficiency was, in all cases, higher than $80 \%$ and in some cases it achieved $100 \%$. This is a very good result with respect to the potential application of lignitic humic acids as an environmentallyfriendly adsorbent for heavy metals. It was found that the leaching of metal ions from humic acids into water was very low; in most of cases it was about $10 \%$ and did not exceed $20 \%$. The majority of metal ions ( $\geq 60 \%$ ) were bound very strongly and only partially leachable under strongly acidic conditions.

\section{Conclusions}

Humic acids isolated from lignite were investigated in order to evaluate their use as an environmentally-friendly adsorbent of heavy metals. Lignite, as a young coal type, contains a relatively high amount of humic acids and can be used for the low-cost production of these valuable substances. It was found that their adsorption efficiency is very high, usually between 80 and $100 \%$. The stability of the formed complexes was evaluated on the basis of leaching using different extraction agents. Copper and lead were bound very strongly in metal ion-humic complexes and their leaching was low. On the other hand, the amount of cadmium and zinc in the mobile and ion-exchangeable phases was higher (in comparison with copper) but this amount did not exceed $40 \%$ of the total content of cadmium and zinc in humic acids. It was confirmed that lignitic humic acids are suitable adsorbent for heavy metals and can be used also for cleaning of waters, soils, and other systems with low or residual concentrations of metal ions. Their partial binding in the mobile and ionexchangeable phases can be compensated for or eliminated by the use of fresh humic acids without the possibility of the backward leaching of metal ions into the cleaned system.

\section{Competing Interests}

The authors declare no conflict of interests regarding the publication of this paper.

\section{Authors' Contributions}

Marcela Pavlíková and Martina Klućáková performed the experiments; Marcela Pavlíková and Martina Klučáková analyzed the data; Martina Klučáková wrote the paper.

\section{Acknowledgments}

This research was supported by Materials Research Centre at FCH BUT-Sustainability and Development, REG LO1211, with financial support from National Programme for Sustainability I (Ministry of Education, Youth and Sports).

\section{References}

[1] M. A. Ferro-García, J. Rivera-Utrilla, I. Bautista-Toledo, and C. Moreno-Castilla, "Adsorption of humic substances on activated carbon from aqueous solutions and their effect on the removal of Cr(III) ions," Langmuir, vol. 14, no. 7, pp. 1880-1886, 1998.

[2] M. Klučáková and L. Omelka, "Study of sorption of metal ions on lignite and humic acids," Chemical Papers, vol. 58, no. 3, pp. 170-175, 2004.

[3] E. A. Ghabbour and G. Davies, "Environmental insights from Langmuir adsorption site capacities," Colloids and Surfaces A: Physicochemical and Engineering Aspects, vol. 381, no. 1-3, pp. 37-40, 2011.

[4] M. Klučáková and M. Pekař, "New model for equilibrium sorption of metal ions on solid humic acids," Colloids and Surfaces A: Physicochemical and Engineering Aspects, vol. 286, no. 1-3, pp. 126-133, 2006.

[5] E. Pehlivan and G. Arslan, "Removal of metal ions using lignite in aqueous solution-low cost biosorbents," Fuel Processing Technology, vol. 88, no. 1, pp. 99-106, 2007.

[6] M. Pekař and M. Klučáková, "Comparison of copper sorption on lignite and on soils of different types and their humic acids," Environmental Engineering Science, vol. 25, no. 8, pp. 1123-1128, 2008.

[7] M. Havelcová, J. Mizera, I. Sýkorová, and M. Pekař, "Sorption of metal ions on lignite and the derived humic substances," Journal of Hazardous Materials, vol. 161, no. 1, pp. 559-564, 2009.

[8] S. Babel and T. A. Kurniawan, "Low-cost adsorbents for heavy metals uptake from contaminated water: a review," Journal of Hazardous Materials, vol. 97, no. 1-3, pp. 219-243, 2003. 
[9] L. Doskočil and M. Pekař, "Removal of metal ions from multicomponent mixture using natural lignite," Fuel Processing Technology, vol. 101, pp. 29-34, 2012.

[10] J. Mizera, G. Mizerová, V. Machovič, and L. Borecká, "Sorption of cesium, cobalt and europium on low-rank coal and chitosan," Water Research, vol. 41, no. 3, pp. 620-626, 2007.

[11] D. Mohan and S. Chander, "Removal and recovery of metal ions from acid mine drainage using lignite - a low cost sorbent," Journal of Hazardous Materials, vol. 137, no. 3, pp. 1545-1553, 2006.

[12] M. Pekař, M. Klucáková, G. Barancíková, M. Madaras, and J. Makovníková, "Affinity of soil and lignitic humic acids for $\mathrm{Cu}(\mathrm{II})$ and Cd(II) ions," in Humic Substances. Molecular Details and Applications in Land and Water Conservation, E. Ghabbour and G. Davies, Eds., pp. 211-223, Taylor and Francis, New York, NY, USA, 2005.

[13] J. Čežíková, J. Kozler, L. Madronová, J. Novák, and P. Janoš, "Humic acids from coals of the North-Bohemian coal fieldII. Metal-binding capacity under static conditions," Reactive \& Functional Polymers, vol. 47, no. 2, pp. 111-118, 2001.

[14] A. G. S. Prado and C. Airoldi, "Humic acid-divalent cation interactions," Thermochimica Acta, vol. 405, no. 2, pp. 287-292, 2003.

[15] H. Martyniuk and J. Wieckowska, "Adsorption of metal ions on humic acids extracted from brown coals," Fuel Processing Technology, vol. 84, no. 1-3, pp. 23-36, 2003.

[16] V. N. Kislenko and L. P. Oliinyk, "Binding of copper(II), cobalt(II), and nickel(II) cations with humic acids and their sodium salts in aqueous media," Russian Journal of Applied Chemistry, vol. 76, no. 12, pp. 1962-1964, 2003.

[17] M. Klučáková, "Adsorption of nitrate on humic acids studied by flow-through coulometry," Environmental Chemistry Letters, vol. 8, no. 2, pp. 145-148, 2010.

[18] M. Klučáková, M. Kaláb, M. Pekař, and L. Lapčík, "Study of structure and properties of humic and fulvic acids. II. Complexation of $\mathrm{Cu}^{2+}$ ions with humic acid extracted from lignite," Journal of Polymer Materials, vol. 19, no. 3, pp. 287-294, 2002.

[19] M. Klučáková and M. Pekař, "Study of structure and properties of humic and fulvic acids. III. Study of complexation of $\mathrm{Cu}^{2+}$ ions with humic acids in sols," Journal of Polymer Materials, vol. 20, no. 2, pp. 145-153, 2003.

[20] A. Liu and R. D. Gonzalez, "Modeling adsorption of copper(II), cadmium(II) and lead(II) on purified humic acid," Langmuir, vol. 16, no. 8, pp. 3902-3909, 2000.

[21] B. Shi, H. E. Allen, M. T. Grassi, and H. Ma, "Modeling copper partitioning in surface waters," Water Research, vol. 32, no. 12, pp. 3756-3764, 1998.

[22] M. Kalina, M. Klučáková, and P. Sedláček, "Utilization of fractional extraction for characterization of the interactions between humic acids and metals," Geoderma, vol. 207-208, no. 1, pp. 92-98, 2013.

[23] P. Janoš, J. Sypecká, P. Mlčkovská, P. Kuráň, and V. Pilařová, "Removal of metal ions from aqueous solutions by sorption onto untreated low-rank coal (oxihumolite)," Separation and Purification Technology, vol. 53, no. 3, pp. 322-329, 2007.

[24] P. Janoš, L. Herzogová, J. Rejnek, and J. Hodslavská, “Assessment of heavy metals leachability from metallo-organic sorbentiron humate-with the aid of sequential extraction test," Talanta, vol. 62, no. 3, pp. 497-501, 2004.

[25] M. A. Shaker and H. M. albishri, "Dynamics and thermodynamics of toxic metals adsorption onto soil-extracted humic acid," Chemosphere, vol. 111, pp. 587-595, 2014.
[26] R. M. Town and H. P. Van Leeuwen, "Intraparticulate speciation analysis of soft nanoparticulate metal complexes. the impact of electric condensation on the binding of $\mathrm{Cd}^{2+} / \mathrm{Pb}^{2+} / \mathrm{Cu}^{2+}$ by humic acids," Physical Chemistry Chemical Physics, vol. 18, no. 15, pp. 10049-10058, 2016.

[27] V. Enev, L. Pospíšilová, M. Klučáková, T. Liptaj, and L. Doskočil, "Spectral characterization of selected humic substances," Soil and Water Research, vol. 9, no. 1, pp. 9-17, 2014.

[28] J. Peuravuori, P. Žbánková, and K. Pihlaja, "Aspects of structural features in lignite and lignite humic acids," Fuel Processing Technology, vol. 87, no. 9, pp. 829-839, 2006.

[29] A. Tessier, P. G. C. Campbell, and M. Blsson, "Sequential extraction procedure for the speciation of particulate trace metals," Analytical Chemistry, vol. 51, no. 7, pp. 844-851, 1979.

[30] G. Rauret, "Extraction procedures for the determination of heavy metals in contaminated soil and sediment," Talanta, vol. 46, no. 3, pp. 449-455, 1998.

[31] J. M. Garcia-Mina, "Stability, solubility and maximum metal binding capacity in metal-humic complexes involving humic substances extracted from peat and organic compost," Organic Geochemistry, vol. 37, no. 12, pp. 1960-1972, 2006.

[32] G. J. Dević, "Characterization of eluted metal ions by sequential extraction from Krepoljin coal basin, Serbia: mechanisms of metal interaction," Energy Sources, Part A: Recovery, Utilization and Environmental Effects, vol. 38, no. 13, pp. 1912-1917, 2016.

[33] D. Dudare and M. Klavins, "Changes in the humic acid-metal complex-forming characteristics depending on the humification degree," Fresenius Environmental Bulletin, vol. 22, no. 2, pp. 604-613, 2013.

[34] L. Pospíšilová, M. Komínková, O. Zítka et al., "Fate of humic acids isolated from natural humic substances," Acta Agriculturae Scandinavica Section B: Soil and Plant Science, vol. 65, no. 6, pp. 517-528, 2015.

[35] G. O. Bosire, B. V. Kgarebe, and J. C. Ngila, "Experimental and theoretical characterization of metal complexation with humic acid," Analytical Letters, vol. 49, no. 14, pp. 2365-2376, 2016.

[36] R. Yang and C. M. G. Van Den Berg, "Metal complexation by humic substances in seawater," Environmental Science and Technology, vol. 43, no. 19, pp. 7192-7197, 2009.

[37] I. S. Kostić, T. D. Andelković, R. S. Nikolić, T. P. Cvetković, D. D. Pavlović, and A. L. Bojić, "Comparative study of binding strengths of heavy metals with humic acid," Hemijska Industrija, vol. 67, no. 5, pp. 773-779, 2013.

[38] A. Terbouche, S. Djebbar, O. Benali-Baitich, and D. Hauchard, "Complexation study of humic acids extracted from forest and Sahara soils with zinc (II) and cadmium (II) by differential pulse anodic stripping voltammetry (DPASV) and conductimetric methods," Water, Air, and Soil Pollution, vol. 216, no. 1-4, pp. 679-691, 2011.

[39] Z.-L. Ren, Y. Sivry, J. Dai et al., "Exploring Cd, Cu, Pb, and Zn dynamic speciation in mining and smelting-contaminated soils with stable isotopic exchange kinetics," Applied Geochemistry, vol. 64, pp. 157-163, 2015. 

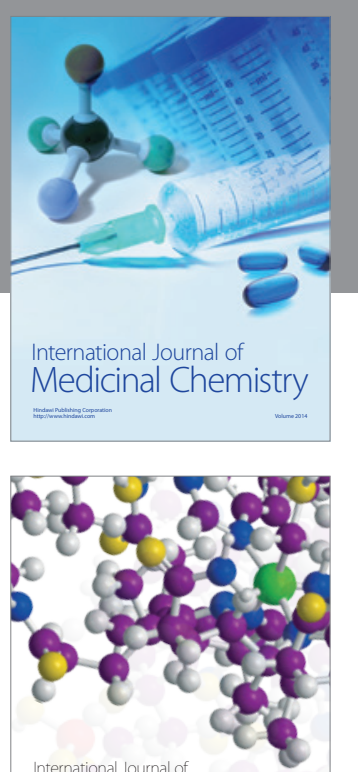

Carbohydrate Chemistry

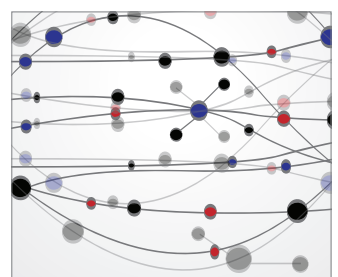

The Scientific World Journal
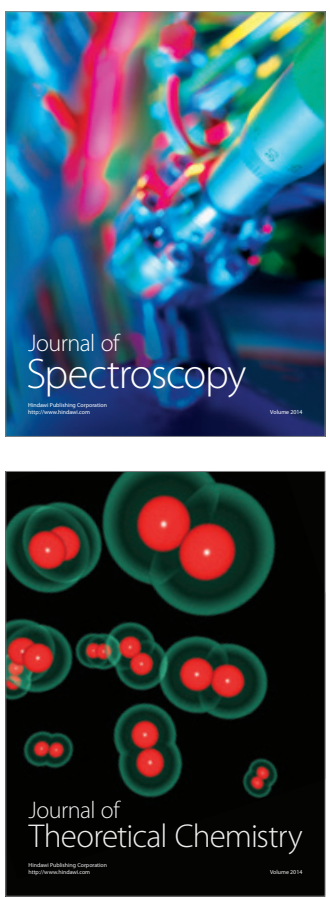
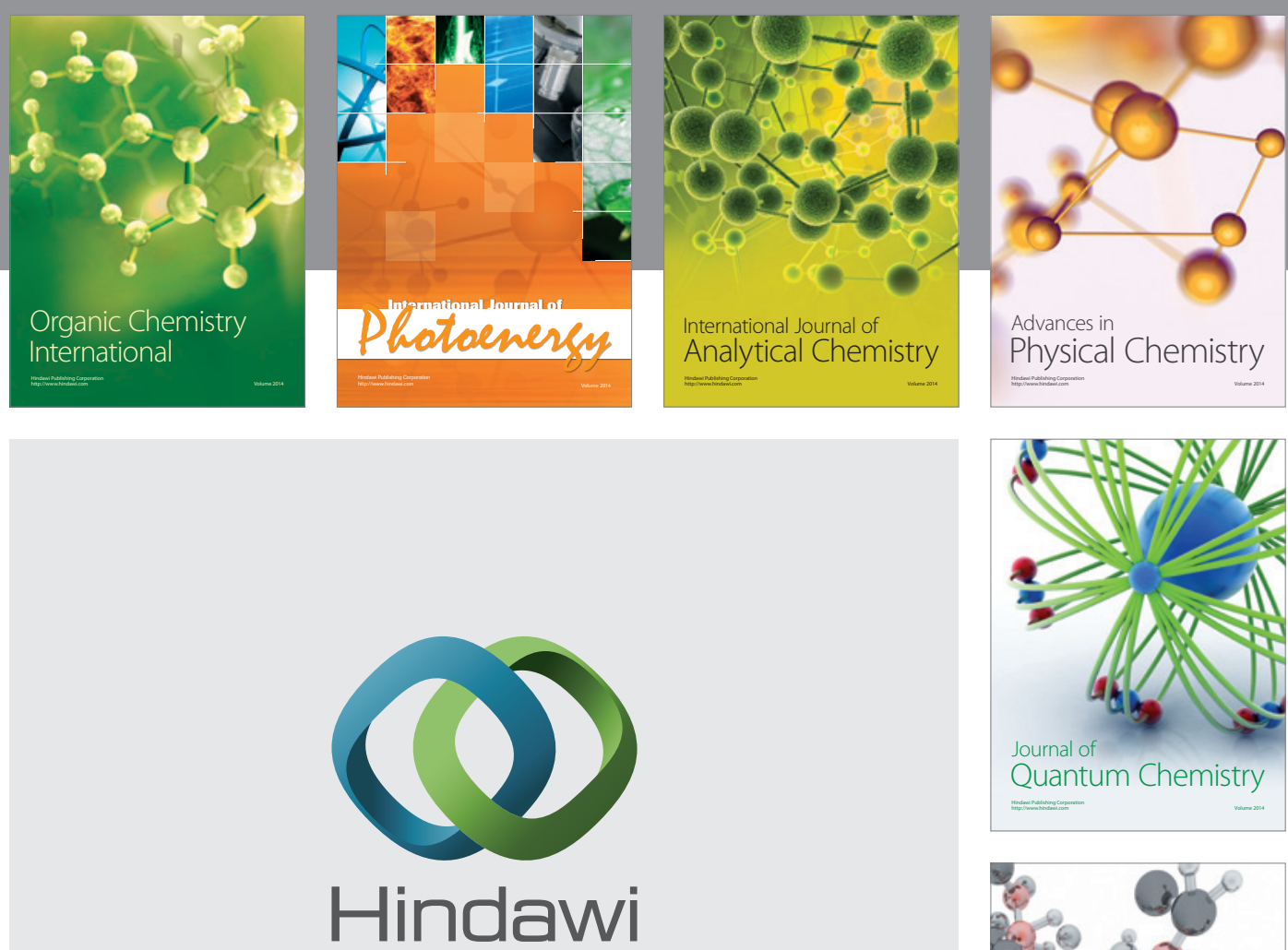

Submit your manuscripts at

https://www.hindawi.com

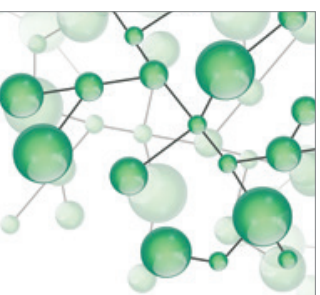

International Journal of

Inorganic Chemistry
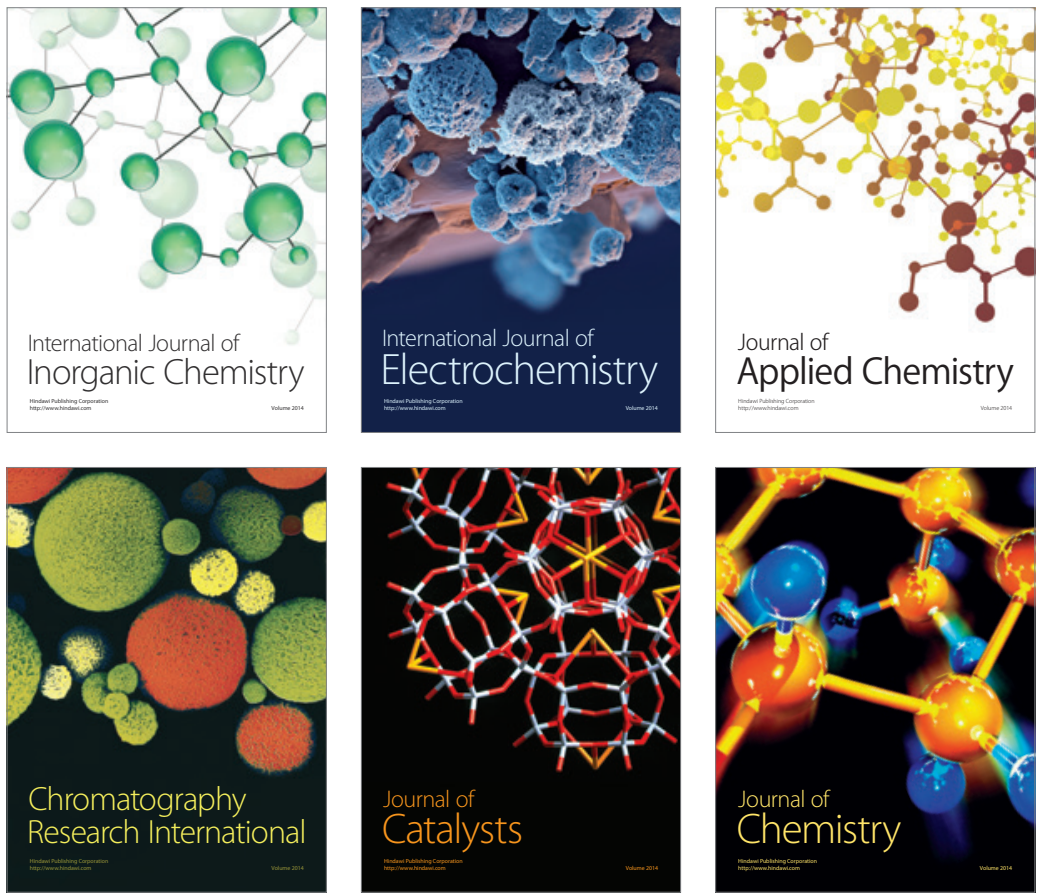

Journal of

Applied Chemistry
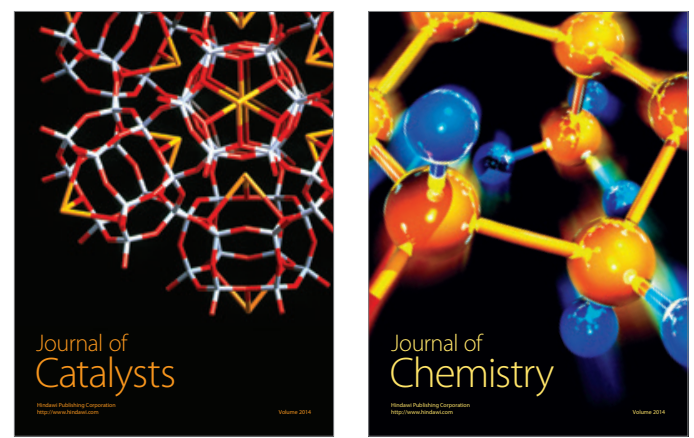
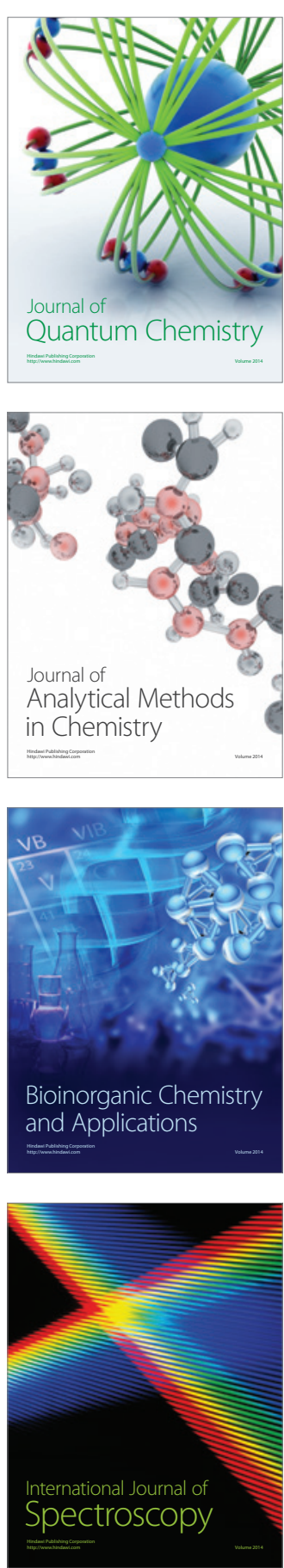